\title{
Coda wave attenuation's dependency on Lapse time and frequency in west of Iran plateau using local earthquakes
}

\author{
Rouhollah Amiri Fard ${ }^{1}$, Gholam Javan-Doloei*,1, Mohsen Farrokhi ${ }^{2}$, Habib Rahimi ${ }^{3}$, \\ Majid Mahood ${ }^{1}$ \\ (1) International Institute of Earthquake Engineering and Seismology, Postal Code: 1953714453 Tehran, I.R. IRAN \\ (2) Dept. of Physics, University of Hormozgan, Bandar Abbas, Iran \\ (3) Institute of Geophysics, University of Tehran, Tehran, Iran
}

Article history: received March 17, 2019; accepted January 22, 2020

\begin{abstract}
In this study, the attenuation of coda waves has been estimated in the western part of Iran plateau using single backscattering method. Coda wave attenuation was estimated at seven central frequencies $\left(f_{c}=1.5,3,4.5,6,9,12,18 \mathrm{~Hz}\right)$ and eight lapse times $\left(t_{l}=10,20,30,40,50\right.$, $60,70,80 \mathrm{~s})$. More than 9100 local earthquakes with magnitude range 2-5.5 and epicentral distance less than $200 \mathrm{~km}$ have been used in this study. The frequency dependency relation of attenuation has been determined by using $Q_{0} f^{n}$ where the $Q_{0}$ and $\mathrm{n}$ are varying from 51 to 225 and from 0.71 to 1.12 for lapse times from 10 to $80 \mathrm{~s}$. The obtained low $Q_{0}$ and high $n$ values indicate that the study region is characterized by high seismic attenuation and, therefore, it is comparable with other seismically active areas.

In order to investigate the attenuation at different depths, two datasets with epicentral distance less than $100 \mathrm{~km}$ and between 100 and $200 \mathrm{~km}$ were separately used. In the next step by using ellipsoidal sampled region, the variation of coda wave attenuation with depth are explored form the first dataset (epicentral distance less than $100 \mathrm{~km}$ ). A slight decrease in the value of estimated attenuation was observed at depth of $\sim 74 \mathrm{~km}$ in Western Alborz (WA) which may be related to high dissipating medium. Also an attenuation anomaly was found at Zagros and Sanandaj-Siran Zone (SSZ) at depth of $\sim 136$ and $\sim 145 \mathrm{~km}$, respectively, which may be related to the low-velocity zone caused by partial melting of the remnant of the fossil Neo-Tethyan. Using the second dataset (epicentral distance between 100 and $200 \mathrm{~km}$ ), a clear decrease in the value of $Q_{0}$ observed at depth of $178 \mathrm{~km}$ in SSZ, which may coincide with the bottom of Arabian lithosphere.
\end{abstract}

Keywords: Attenuation, Coda wave, Single back-scattering, Iran plateau

\section{Introduction}

Seismic wave attenuation is one of the most important properties of seismic waves. The seismic wave attenuation 


\section{Rouhollah Amiri Fard et al.}

can provide important information which is necessary for interpretation of the rate of seismicity and heterogeneity within the crust and upper mantle. Therefore, estimation of the seismic wave attenuation has been widely used to investigate the source mechanism of earthquakes, seismic risk analysis, and engineering seismology [Singh and Herrmann, 1983; Jin and Aki, 1988; Rahimi and Hamzehloo, 2008; Rahimi et al., 2010].

The amplitude of seismic wave decreases as travel distance increases in a rate higher than those of geometrical spreading. This decay arises from elastic and anelastic properties of the medium. In the elastic medium, seismic energy is dispersed (is not dissipated) due to inhomogeneities (scattering attenuation; $Q_{S c}{ }^{-1}$ ), whereas in the anelastic medium, it dissipates due to the conversion of kinematic energy into heat [Farrokhi et al., 2015] which is known as intrinsic absorption $\left(Q_{i}^{-1}\right)$. The attenuation, which is generally expressed by the inverse of the quality factor $\left(Q_{t}^{-1}\right)$, is a combination of intrinsic absorption and scattering attenuation $\left(Q_{t}^{-1}=Q_{S c}{ }^{-1}+Q_{i}^{-1}\right)$.

Coda waves, which are defined as continuous wave trains following direct $\mathrm{P}$ and $\mathrm{S}$ waves, are composed of scattered waves due to the numerous heterogeneities existed within the propagating media [Aki, 1969]. The amplitude of coda waves are independent of epicentral distance for local earthquakes and decrease as lapse time (determined from the event origin time) increase [Aki, 1969; Sato et al., 2012]. The attenuation of coda waves $\left(Q^{-1} c\right)$ are estimated by using decay rate analysis of coda waves amplitudes. Generally, there are two models for interpretation of coda wave generation at low lapse times. First, single back-scattering model [Aki and Chouet, 1975] and second, single isotropic scattering [Sato, 1977]. The initial idea of the single back-scattering method was based on the assumption that source and receiver are co-located, but assumption of non-collocated source and station is used in single isotropic scattering. This is a reliable assumption for coda wave which comes long after arrival time of S-wave. In shorter lapse time we have to use non-collocated source and station pairs which is known as single isotropic method and was introduced by Sato [1977]. Sato [1988] reported the $Q_{c}$ values derived by the Single Isotropic Scattering (SIS) method converge to those of the Single Backscattering (SBS) method for long lapse times, whereas Farrokhi, et al. [2015] have reported the same approach at lapse times greater than $2 t_{s}$ (tc $>30 \mathrm{~s}$ ). Gao et al. [1983] found that the extension of the single scattering theory might explain coda power for shorter lapse times whereas multiple scattering needs to be considered for larger lapse times ( $>100 \mathrm{~s}$ ) [Chung et al., 2009]. It has been also reported that coda waves are mostly composed of multiple scattering at latter lapse times [Wu, 1985]. Wennerberg [1993] introduced a method for separation of intrinsic and scattering attenuation and reported that intrinsic attenuation $\left(Q_{i}^{-1}\right)$ has a good correlation with coda wave attenuation $\left(Q_{c}^{-1}\right)$ when the major part of $S$-wave attenuation is caused by intrinsic attenuation. Later, Mukhopadhyay et al. [2006] observed that coda wave attenuation is close to the value of intrinsic attenuation by means of analyzing local earthquake waveforms. Moreover, Shapiro et al. [2000] have shown that coda wave attenuation at very long lapse time is predominantly influenced by intrinsic absorption.

Generally, the attenuation of coda waves has a strong correlation with the geological setting of the study area [Jin and Aki, 1988]. The attenuation of coda waves $\left(Q_{c}^{-1}\right)$ seems to have frequency dependency in form of $Q=Q_{0}$ for $f>1 \mathrm{~Hz}$. The $Q_{0}$ is attenuation at frequency $1 \mathrm{~Hz}$ and $n$ is frequency relation parameter that is related to the degree of heterogeneity of the crust [Aki, 1981]. It has been reported that tectonically active regions has low $Q_{0}\left(Q_{0}<200\right)$ but very high $Q$ values were reported for stable regions [Sato et al., 2012; Farrokhi et al. 2015]. The logical reason for this observation is that tectonically active regions are mostly composed of faulted and folded regions with low $Q$ factors, but the stable regions are composed of uniform media with high $Q$ values [Farrokhi et al., 2015].

The main objective of this research is to study coda wave attenuation in the western part of Iran using the single backscattering method. This area is one of the most seismically active regions of Iran, including several metropolitan areas (e.g. Tehran, Tabriz, Kermansha, Arak, and Ahwaz as shown in Figure 1). Based on the results of Hamzehloo et al. [2012] the rate of seismic hazard in the west of Iran is high. Several large destructive earthquakes with magnitude higher than 6 have occurred in the area of study since 1900 (International Institute of Earthquake Engineering and Seismology (IIEES) catalog; http://www.iiees.ac.ir/en/eqcatalog). The western part of Iran is divided into four subregion by using geological and seismo-tectonical characteristics, named Zagros, Sanandaj Sirjan Zone (SSZ), North West of Central Iran (NWCI) and Western Alborz (WA). Shad Manaman et al. [2011] reported that the Zagros and SSZ have lower velocities than Alborz and Central Iran at depths less than $50 \mathrm{~km}$, whereas for upper mantle Zagros and SSZ have faster velocities than Alborz and Central Iran. They have also estimated the crustal thickness of the Iran plateau from 30 to $70 \mathrm{~km}$ beneath the center of the South Caspian Basin and SSZ, respectively. In recent years, several studies have been done to assess seismological characteristics of Iran plateau [Alavi and Kishvar, 1991; Hessami et al., 2003; Hamzehloo et al., 2012; Fard et al., 2015; Kaviani et al., 2015]. Coda wave attenuation has been estimated 
at many regions of Iran using different dataset and methods [Ma'hood et al., 2009; Rahimi et al., 2010; Farrokhi et al., 2015; Irandoust et al., 2016; Naghavi et al., 2017; Amiri Fard et al., 2019; Ahmadzadeh et al., 2017 \& 2019].

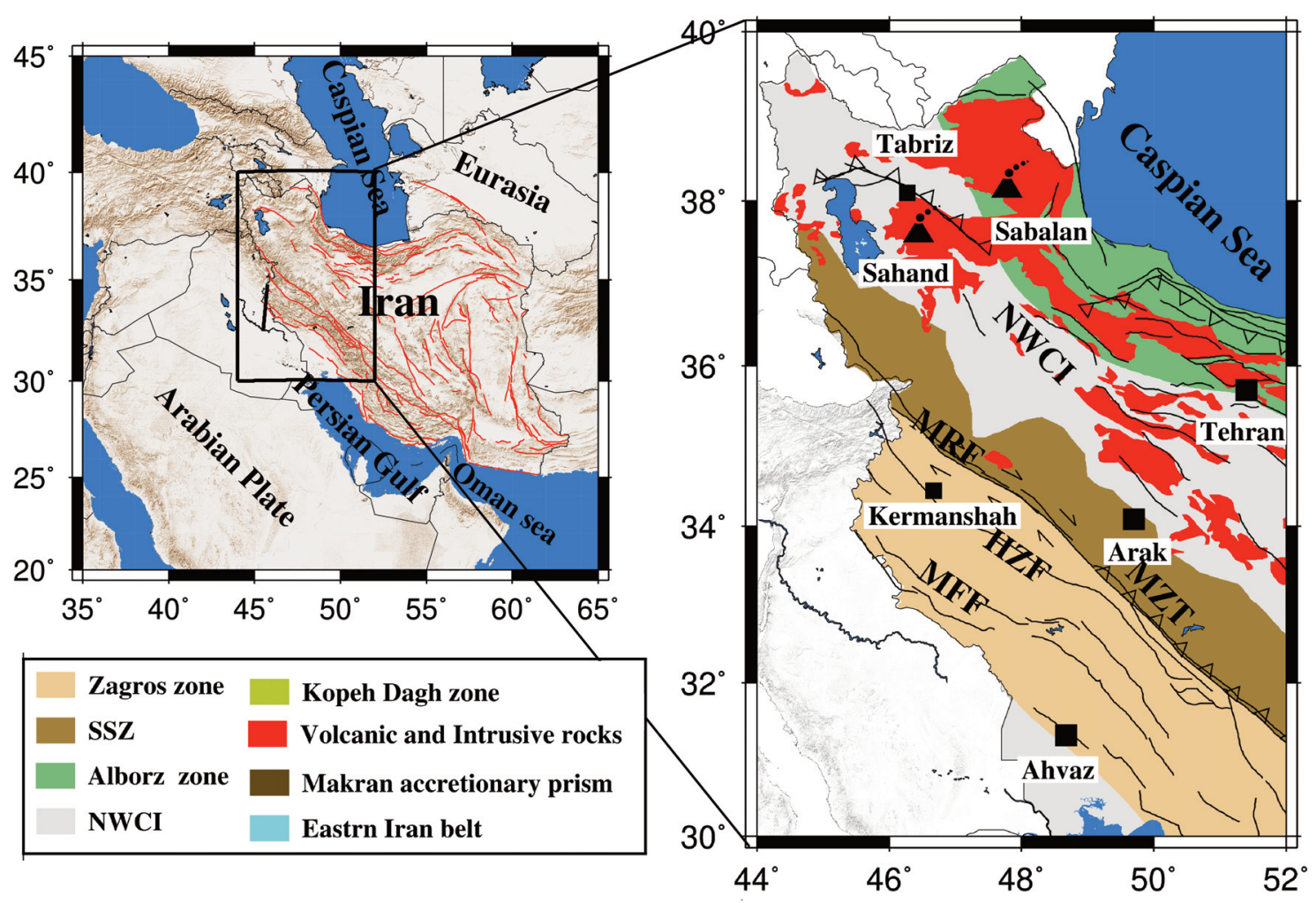

Figure 1. Geological map modified from the structural map of National Geoscience Database of Iran (NGDI, http://www.ngdir.ir). The area of study is shown by black rectangle. NTF, MRF, and MZT are North Tabriz Fault, Main Recent Fault, and Main Zagros Thrust, respectively. NWCI is North West of Central Iran.

The high seismic hazard, existence of high populated cities within this area, and occurrence of destructive earthquakes motivate more seismic investigations of this region. In the present study, the variation of coda wave quality factor is estimated in the west of Iran. Since the study area is vast and has different tectonic characteristics, the area has divided into four sub-regions (West Alborz (WA), North West of Central Iran (NWCI), Sanandaj Sirjan Zone (SSZ) and Zagros) based on their geological and tectonic characteristics. It should be noted that the earthquakes and stations within the borders of sub-regions are used for region-wise analysis. Coda wave attenuation was estimated for each sub-region and the relation between tectonic setting and obtained coda wave attenuation is interpreted. In this study more than 9100 local earthquakes with magnitude less than 5.5 and epicentral distances less than $200 \mathrm{~km}$ have been used.

\section{Seismotectonic setting}

Iran plateau (Figure 1) is located within Alpine-Himalayan orogenic belt which is the result of collision and convergence between Arabian and Eurasian plates [Stampfli and Borel, 2002; Allen et al., 2004]. The Arabia-Eurasia collision, which is the sequence of the closing of Neo-Tethys in late Cretaceous started from late Miocene. This closure leads various tectonic processes such as subduction of oceanic lithosphere and continental collision. The rate of this convergence is reported as $22 \pm 2 \mathrm{~mm} \mathrm{yr}^{-1}$ at the longitude of Hormoz Strait by Vernant et al. [2004]. The Zagros and the Alborz mountain ranges accommodate about one-third of this convergence at the longitude of Tehran. This collision has provided the necessary energy to raise the Zagros and Alborz Mountain ranges. Five major 
fault systems in the Zagros region are the Main Recent Fault (MRF), the Main Zagros thrust (MZT), High Zagros fault (HZF), Main Front Fault (MFF) and Kazerun-Borazjan, respectively (Figure 1). These faults absorb approximately 10 $\mathrm{mm} / \mathrm{yr}$ of convergence in Zagros [Vernant et al., 2004].

Seismic studies indicate a very high seismic activities (Figure 2) with shallow depth and medium to large magnitude in the Zagros [Jackson and Fitch, 1981; Maggi et al., 2000; Talebian and Jackson, 2004]. Seismicity of the Zagros zone shows that most of large earthquakes have occurred along MRF, and MFF. Previous studies and geological maps show that a sequence of Paleozoic and Mesozoic sediments covered the Zagros zone [Berberian and King, 1981; Stoneley, 1981; Bachmanov et al., 2004].

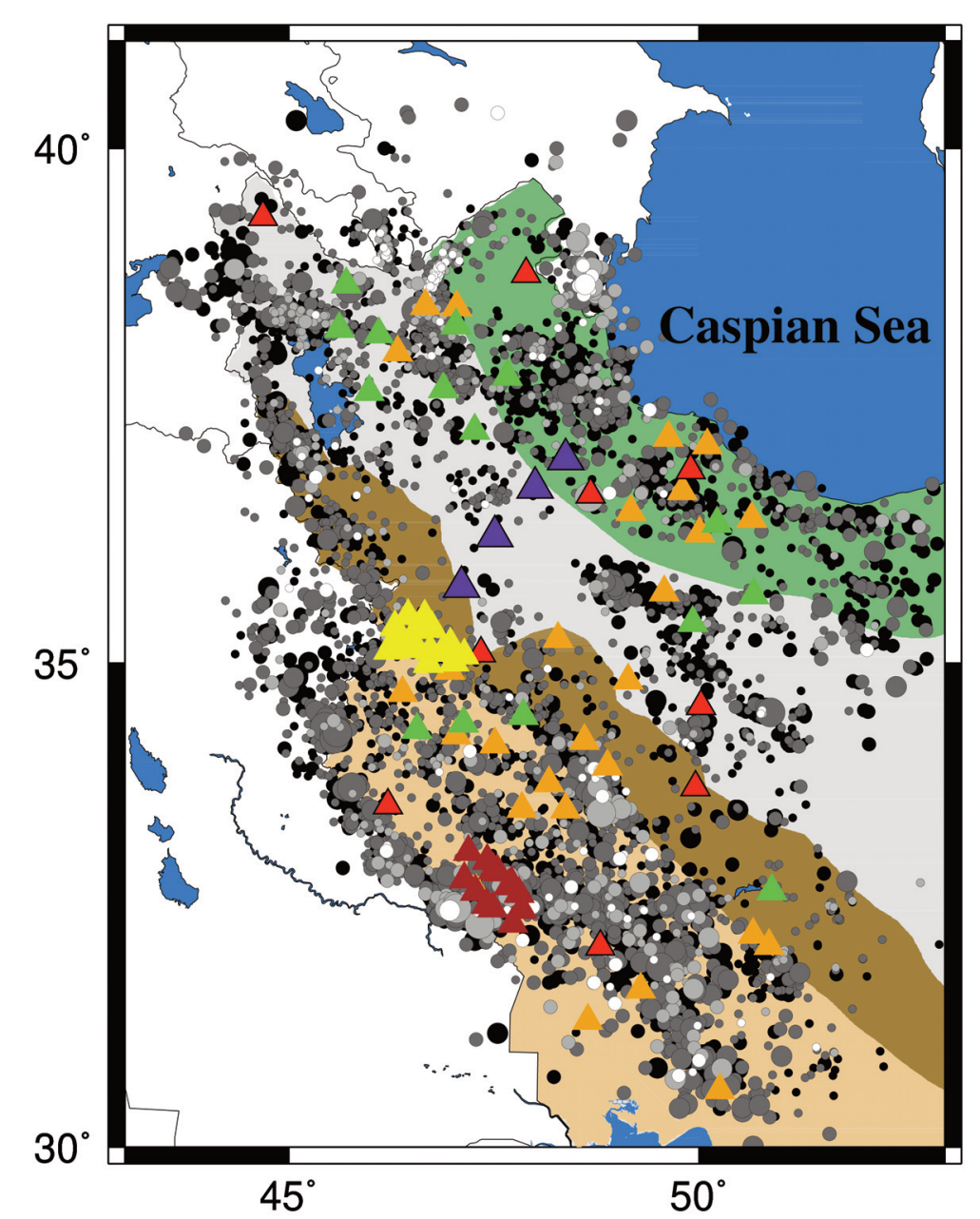

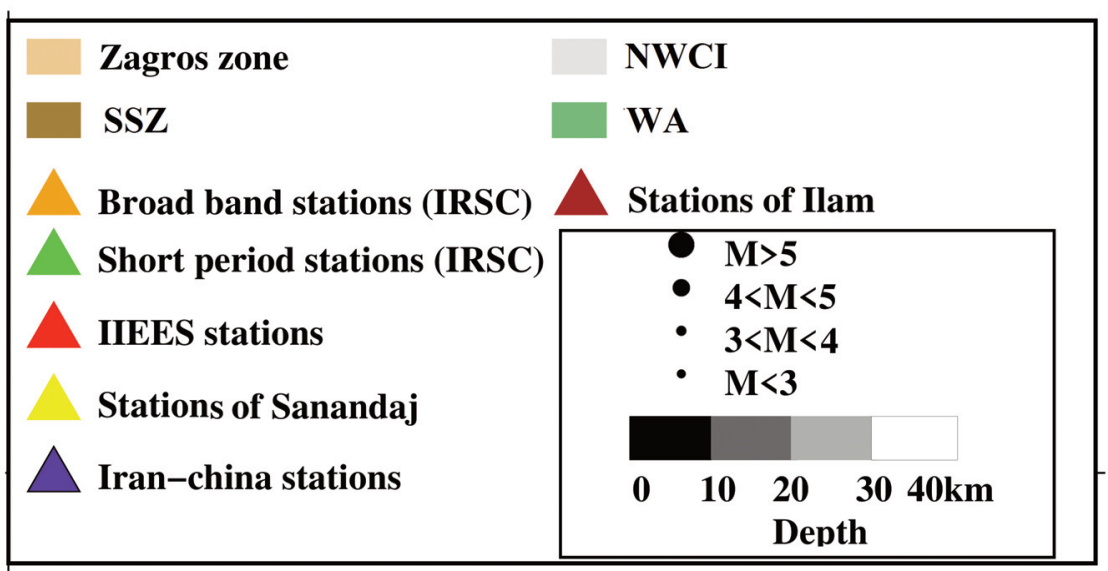

Figure 2. Location map of stations and earthquakes used in this study. 
SanandajSirjan Zone (SSZ) extends in a narrow region (150-200 km wide) which is located parallel to the MZT, and has NW-SE-trending. The SSZ has experienced various metamorphic episodes and coincides with the crustal root of Zagros zone [Stocklin, 1968; Snyder and Barazangi, 1986]. During the last metamorphic episode, SSZ overthrusted the Zagros sedimentary cover [Stocklin, 1968; Agard et al., 2005]. SSZ has mainly covered by sedimentary and metamorphic Paleozoic to Cretaceous rocks. Volcanoes of late Cretaceous and early Miocene age in the SSZ demonstrate the Andean type magmatism in southern Eurasia during Neo-Tethyan subduction [Berberian et al., 1982].

Central Iran covers a roughly triangular area between Alborz and SSZ, which is constituted of several blocks that detached from Gondwana in the Permian to early-Triassic and accreted onto Eurasia in Mesozoic [Stocklin, 1968]. The Central Iran zone consists of rocks of all ages, from Precambrian to Quaternary, and several episodes of orogeny, metamorphism, and magmatism [Bachmanov et al., 2004; Ghorbani, 2013].

Alborz, located in the north of Iran between Caspian Sea and Central Iran with east-west-trending mountain belt, is formed as the result of collision between Central Iran and Eurasia in the late Triassic [Stöcklin, 1974; Şengör et al., 1988]. Alborz is made of volcanic and sedimentary layers from Cambrian to Eocene [Stöcklin, 1974; Berberian, 1983]. In the western end of Alborz, Talesh Mountains and Alborz connect to each other. According to the seismicity maps, Alborz has high seismic activity with shallow depth. It has been postulated that Alborz has both left-lateral strike-slip and thrust faulting [Allen et al., 2003].

\section{Dataset}

The dataset used in this study was recorded by 88 stations (Figure 3) of the following networks which were deployed in North and West of Iran plateau:
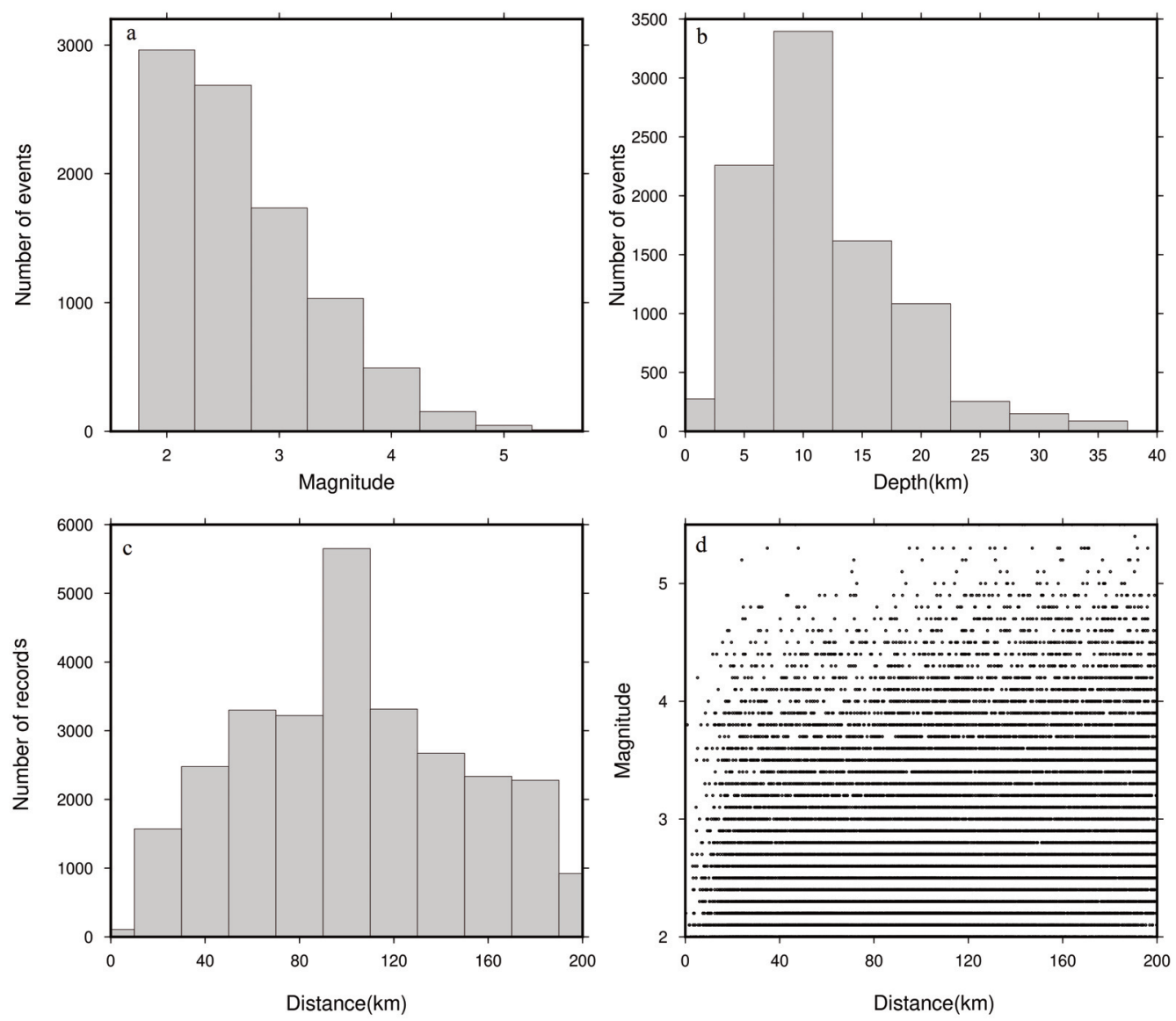

Figure 3. (a) Number of events versus magnitude, (b) The depth distribution of events, (c) Number of records versus magnitude, and (d) Magnitude of each record versus epicentral distance. 


\section{Rouhollah Amiri Fard et al.}

1) We used the waveforms of 30 broad-band (Guralp CMG-3T; 0.02-100 s) and 15 short-period (Kinemetrics SS-1) seismic stations from the permanent network of Iranian Seismological Center (IRSC).

2) We have processed the waveforms of 9 broad-band seismometers from the National Center of Broadband Seismic Network of Iran (BIN), which are equipped with Guralp CMG-3T broad-band sensors (0.02-100s) and DM24 digitizers. Our dataset from permanent seismic networks were prepared from 1 January 2006 to 31 December 2015.

3) The temporary seismic networks consist of 16, 14 and 4 seismic stations from Sanandaj, Ilam, and Iran-China networks, respectively. These stations are equipped with Guralp CMG-6TD portable seismic instrument with sampling rates of $100 \mathrm{~Hz}$.

The Sanandaj and Ilam networks were installed from 1 January 2012 to 31 December 2015 and October 10, 2014 to October 21, 2014, respectively by the International Institute of Earthquake Engineering and Seismology (IIEES). The Iran-China network operated from 1 October 2013 to 31 October 2014, by Institute for Advanced Studies in Basic Sciences (IASBS) and Geological Survey of Iran (GSI) as local organizer.

Our dataset, consisting of more than 27900 records, was used to estimate coda wave quality factor $\left(Q_{c}\right)$. The earthquakes have magnitude between 2 and 5.5, epicentral distance less than $200 \mathrm{~km}$, and average focal depth of $12 \mathrm{~km}$. Number of events versus magnitude and depth, number of records versus magnitude, and magnitude of each record versus epicentral distance are displayed in Figure 3.

\section{Methodology}

In this research, the single backscattering model [Aki and Chouet, 1975] has been used to estimate the coda wave attenuation of 9100 local earthquakes. In this method, it is assumed that source and receiver are at the same point and scattering is a weak process that does not produce any secondary scattering. According to this model, the decay rate of root mean square (RMS) amplitude of coda wave $A(f, t)$ for a central frequency of $f$ at lapse time $t_{l}$ is defined as the following:

$$
A(f, t)=C(f) t_{l}^{-\alpha} \exp \left(\frac{-\pi f t_{l}}{Q_{c}}\right)
$$

Where $C(f), \alpha$, and $Q_{c}$ are the source factor, geometrical spreading ( $\alpha=1$ for body wave), and the coda quality factor, respectively. If natural logarithm is taken from both sides of Eq. (1), it becomes:

$$
\operatorname{Ln}\left[A\left(f, t_{l}\right) t_{l}\right]=c-b t_{l}
$$

Where $c=\operatorname{Ln} C(f)$ and $b=\frac{\pi f}{Q_{c}}$. For estimation of $Q_{c}$ value at each selected lapse time, a straight line is fitted to the $\operatorname{Ln}\left[A\left(f, t_{l}\right) t_{l}\right]$. The slope of that line (b) gives quality factor value at a central frequency $f$.

In order to calculate $Q_{c}$ in this study, vertical component of each source-station waveform was analyzed. The data processing consists of the following steps:

1) The baseline correction was corrected, then a 3\% cosine taper window was used to avoid Gibbs phenomenon at two cutoff edges of signal.

2) Each waveform was narrow-band filtered using four-pole Butterworth band-pass filter with seven central frequencies of $1.5,3,4.5,6,9,12$, and $18 \mathrm{HZ}$.

3) In this step, Eq. (3) is used to obtain coda wave envelop.

$$
A\left(f, t_{l}\right)=\sqrt{x\left(f, t_{l}\right)^{2}+H\left[x\left(f, t_{l}\right)\right]^{2}}
$$

Where, $\mathrm{x}$ is filtered seismogram with central frequency $f$ and lapse time $t_{l}$, and $\mathrm{H}$ is Hilbert transform function.

4) A root mean square approach based on Eq. (4) is used to smooth the obtained coda envelop. In this approach, a window sliding with $5 \mathrm{~s}$-length and $1 \mathrm{~s}$ intervals is considered, then root mean square of this window is calculated and is attributed to the center of the window. 


$$
A_{c}\left(f, t_{l}\right)=r m s(\text { Coda window })
$$

5) Next, signal to noise ratio (SNR) of coda waves should be determined to select good quality coda wave. A 5-s window length before the P-wave arrival time was considered as the noise window. The root mean square (rms) of noise window was considered as noise amplitude $\left(\mathrm{A}_{\mathrm{N}}\right)$

$$
A_{N}(f)=r m s \text { (Noise window) }
$$

Then, SNR was calculated using the Eq. (6).

$$
\operatorname{SNR}\left(f, t_{l}\right)=\frac{A_{c}\left(f, t_{l}\right)}{A_{N}(f)}
$$

In this study we used coda waves with SNR ratio greater than 2.

6) Finally, each filtered seismogram was cut by selected time windows as defined in Table 1 . It should be noted that we considered only those $A_{c}$ which satisfied the $t_{l}>2 t_{s}$. The coda wave quality factor was estimated by using the slope of the best fitted line to the measured $\operatorname{Ln}\left[A\left(f, t_{l}\right) t_{l}\right]$ versus $t_{l}$ by using Eq. 2 (Table 1 ). As an example of data processing for an earthquake with epicentral distance $21 \mathrm{~km}$ and magnitude 3.9, the results are shown in Figure 4.

It should be noted that the effect of geometrical spreading on the results of attenuation was checked. We examine $\alpha=0.75$ and $\alpha=1$ and found that the $Q_{c}$ results varied in order of standard deviation of $Q_{c}$ values. Accordingly $\alpha=1$ was selected to analyze data.

As shown in Figure $4, Q_{c}$ increases with lapse time. In other words, the quality factor at different lapse time demonstrates

\begin{tabular}{ccc} 
Lapse Time $\left(\mathrm{t}_{\mathbf{l}}\right)$ & Start time & End time \\
\hline 10 & $2 \mathrm{t}_{\mathrm{s}}$ & Start time +10 \\
\hline 20 & $2 \mathrm{t}_{\mathrm{s}}+5$ & Start time +20 \\
\hline 30 & $2 \mathrm{t}_{\mathrm{s}}+10$ & Start time +30 \\
\hline 40 & $2 \mathrm{t}_{\mathrm{s}}+15$ & Start time +40 \\
\hline 50 & $2 \mathrm{t}_{\mathrm{s}}+20$ & Start time +50 \\
\hline 60 & $2 \mathrm{t}_{\mathrm{s}}+25$ & Start time +60 \\
\hline 70 & $2 \mathrm{t}_{\mathrm{s}}+30$ & Start time +70 \\
\hline 80 & $2 \mathrm{t}_{\mathrm{s}}+35$ & Start time +80 \\
\hline 90 & $2 \mathrm{t}_{\mathrm{s}}+40$ & Start time +90 \\
\hline
\end{tabular}

Table 1. Lapse time, start time and end time of each lapse time used in this study.

the average quality factor at the different depths. Pulli [1984] introduced a method to estimate average penetration depth of coda waves. In the present study, we have used this method for calculating the average penetration depth.

At each lapse time, scatters for generation of coda waves are assumed to be distributed on an ellipsoidal surface [Pulli, 1984] whose surface projection is defined as $\alpha_{2}=\left(\alpha_{1}{ }^{2}-\frac{\Delta x^{2}}{4}\right)^{1 / 2}$ for small axis and $\alpha_{1}=\frac{V_{s} \bar{t}}{2}$ for large axis. Here $\Delta x$ and $V_{s}$ are the source-receiver distance and the shear wave velocity (3.5 km/s based on [Tatar, 2001; Doloei and Roberts, 2003; Kaviani, 2004]), respectively. $\bar{t}$ is the average lapse time and it is taken by $\bar{t}=t_{0}+\frac{w}{2}$ where $t_{0}$ is the starting time of coda window and $w$ is the coda window length. The average depth of ellipsoid is determined as $h=\bar{h}+\alpha_{2}$, where $\bar{h}$ is the average focal depth of the events. 

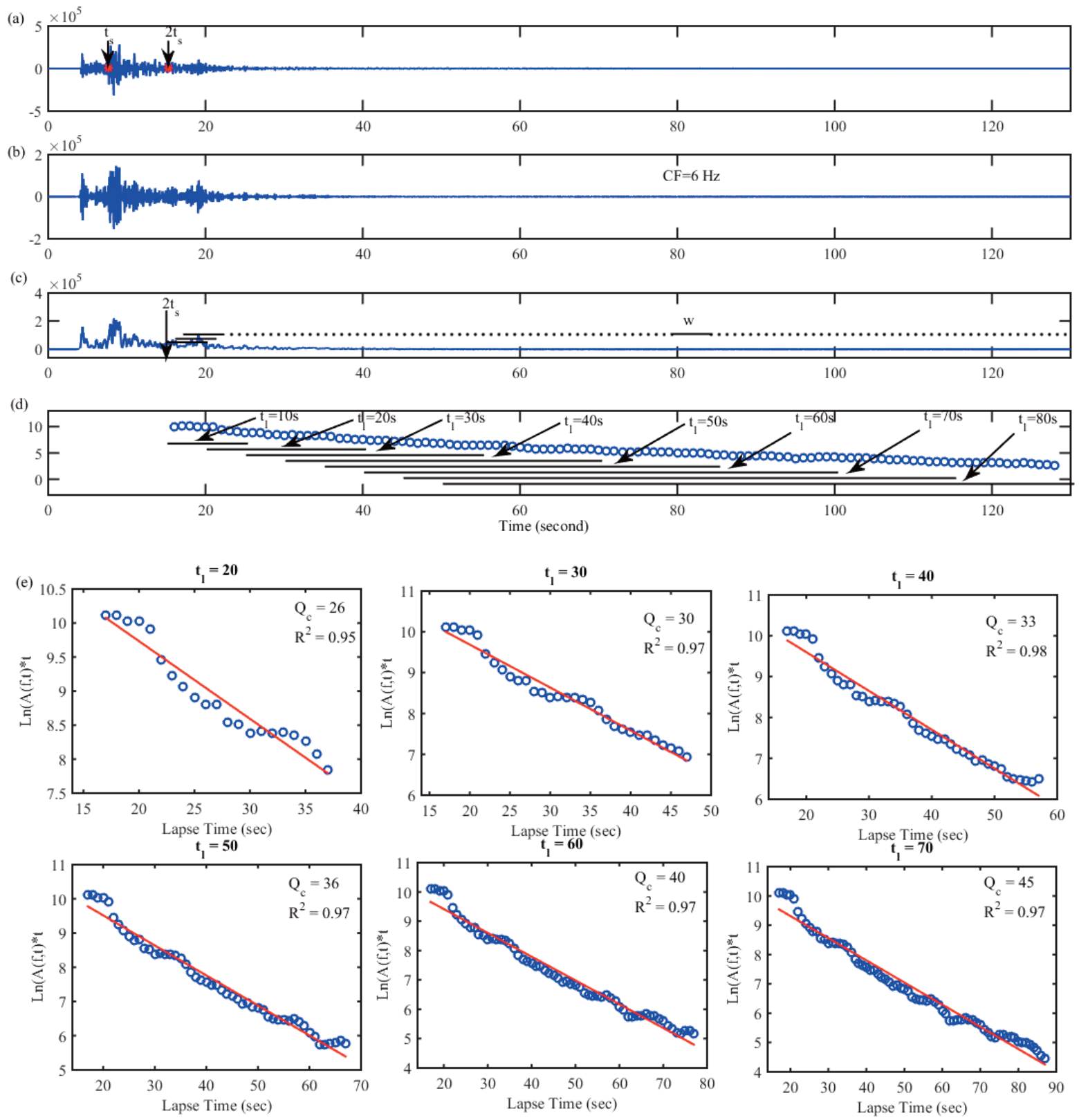

Figure 4. An example of data processing. (a) Raw seismogram with epicentral distance $21 \mathrm{~km}$ and magnitude 3.9 . The $t_{s}$ and $2 t_{s}$ are the $\mathrm{S}$ and coda wave arrival times. (b) bandpass filtered seismogram at $4-8 \mathrm{~Hz}$ (central frequency $6 \mathrm{~Hz}$ ). (c) Obtained coda wave envelop by using Eq. (3). The root mean square (rms) amplitude of coda waves is calculated using a 5 s time window (W) for lapse times. (d) terms amplitudes of coda waves are multiplied by $t$. Each lapse time $(10,20, \ldots, 80 \mathrm{~s})$ used for $Q c$ estimation is shown by a thick and black line. (e) the plots of $\ln \left[A(f, t)^{*} t\right]$ versus lapse time $\left(t_{l}\right)$ and regression analysis for $t_{l}=20,30,40 \ldots 70$ s.

\section{Results and Discussion}

Attenuation properties of high-frequency seismic waves are important parameters to quantify and to physically characterize the earth medium. The Earth does not transmit seismic waves with perfect elasticity; small anelastic losses occur that progressively attenuate the wave energy. This anelasticity causes dispersion, changes pulse shapes, and affects amplitudes of the waves; therefore it can be modeled as well. Unlike the case for seismic velocities, the Earth does not have a simple layered attenuation structure. Various observations in different parts of the world have indicated a striking difference in the rate of amplitude decay between tectonically active and stable regions 
[Sato and Fehler, 2012]. We estimated the amount of coda wave attenuation due to distributed heterogeneities, in a manner consistent with conventional seismological attenuation measurements.

We have used local earthquakes recorded by 88 stations to estimate the mean values of $Q_{c}$ for eight lapse times (Table 1). For this purpose, more than 27900 seismograms at seven frequency bands have been processed. The studied area has been divided into four sub-regions. Figure 5 shows the results of the $Q_{c}{ }^{-1}$ at all lapse time versus frequency and number of data versus lapse time. Our calculation for the average quality factor values (Figure 5) indicate a strong lapse time and frequency dependencies. It is well known that the attenuation is related to the inverse of quality factor. The $Q_{c}^{-1}$ values are plotted versus frequency for short lapse time (blue line) and long lapse times (red line) in Figure 5. It is expected that lower $Q_{c}^{-1}$ values result in the lower attenuation, but the attenuation of coda waves is related to the multiplication of frequency with $Q_{c}^{-1}$ (equation 1 ), therefore the low frequency waves are less attenuated when frequency dependency power (n) becomes less than 1 . This means that in this region low frequencies are less attenuated than high frequencies. We also observed that shorter lapse times are more attenuated that longer lapse times. Moreover, Figure. 5 shows that the number of observations decrease as the lapse time increase, which is due to the lower SNR at larger lapse times. Variation of $Q_{c}^{-1}$ is not uniform among the sub-regions and it depends on the complexity of the region due to relative contribution of different tectonic processes.

\begin{tabular}{|c|c|c|c|c|c|}
\hline$t_{1}$ & & WA & NWCI & SSZ & Zagros \\
\hline \multirow{2}{*}{10} & $Q_{c}$ & $(62 \pm 1) \mathrm{f}^{(0.91 \pm 0.01)}$ & $(58 \pm 1) \mathrm{f}^{(0.97 \pm 0.01)}$ & $(55 \pm 2) \mathrm{f}^{(1.03 \pm 0.01)}$ & $(51 \pm 1) \mathrm{f}^{(1.12 \pm 0.01)}$ \\
\hline & $\mathrm{h}(\mathrm{km})$ & 61 & 59 & 57 & 63 \\
\hline \multirow{2}{*}{20} & $\mathrm{Q}_{\mathrm{c}}$ & $(78 \pm 1) \mathrm{f}^{(0.83 \pm 0.01)}$ & $(88 \pm 1) \mathrm{f}^{(0.76 \pm 0.01)}$ & $(95 \pm 2) \mathrm{f}^{(0.97 \pm 0.01)}$ & $(89 \pm 1) \mathrm{f}^{(1.04 \pm 0.01)}$ \\
\hline & $\mathrm{h}(\mathrm{km})$ & 74 & 77 & 73 & 81 \\
\hline \multirow{2}{*}{30} & $Q_{c}$ & $(109 \pm 1) \mathrm{f}^{(0.78 \pm 0.1)}$ & $(114 \pm 1) \mathrm{f}^{(0.72 \pm 0.01)}$ & $(131 \pm 3) f^{(0.91 \pm 0.02)}$ & $(120 \pm 1) \mathrm{f}^{(0.98 \pm 0.01)}$ \\
\hline & $\mathrm{h}(\mathrm{km})$ & 104 & 94 & 91 & 100 \\
\hline \multirow{2}{*}{40} & $\mathrm{Q}_{\mathrm{c}}$ & $(125 \pm 1) f^{(0.75 \pm 0.01)}$ & $(136 \pm 1) \mathrm{f}^{(0.75 \pm 0.01)}$ & $(155 \pm 2) f^{(0.88 \pm 0.01)}$ & $(145 \pm 2) f^{(0.97 \pm 0.01)}$ \\
\hline & $\mathrm{h}(\mathrm{km})$ & 122 & 111 & 109 & 118 \\
\hline \multirow{2}{*}{50} & $\mathrm{Q}_{\mathrm{c}}$ & $(136 \pm 1) f^{(0.74 \pm 0.01)}$ & $(154 \pm 2) f^{(0.77 \pm 0.01)}$ & $(181 \pm 3) \mathrm{f}^{(0.90 \pm 0.2)}$ & $(167 \pm 2) \mathrm{f}^{(1.01 \pm 0.02)}$ \\
\hline & $\mathrm{h}(\mathrm{km})$ & 139 & 129 & 127 & 136 \\
\hline \multirow{2}{*}{60} & $Q_{c}$ & $(142 \pm 2) \mathrm{f}^{(0.73 \pm 0.1)}$ & $(158 \pm 2) \mathrm{f}^{(0.78 \pm 0.01)}$ & $(202 \pm 4) \mathrm{f}^{(0.87 \pm 0.1)}$ & $(176 \pm 3) \mathrm{f}^{(1.0 \pm 0.01)}$ \\
\hline & $\mathrm{h}(\mathrm{km})$ & 157 & 147 & 145 & 155 \\
\hline \multirow{2}{*}{70} & $Q_{c}$ & $(147 \pm 2) \mathrm{f}^{(0.72 \pm 0.01)}$ & $(161 \pm 3) \mathrm{f}^{(0.78 \pm 0.01)}$ & $(209 \pm 4) \mathrm{f}^{(0.85 \pm 0.03)}$ & $(180 \pm 2) \mathrm{f}^{(0.98 \pm 0.01)}$ \\
\hline & $\mathrm{h}(\mathrm{km})$ & 175 & 165 & 162 & 173 \\
\hline \multirow{2}{*}{80} & $Q_{c}$ & $(158 \pm 3) \mathrm{f}^{(0.72 \pm 0.01)}$ & $(165 \pm 2) \mathrm{f}^{(0.76 \pm 0.01)}$ & $(217 \pm 3) \mathrm{f}^{(0.82 \pm 0.01)}$ & $(190 \pm 3) f^{(0.97 \pm 0.01)}$ \\
\hline & $\mathrm{h}(\mathrm{km})$ & 192 & 182 & 180 & 191 \\
\hline
\end{tabular}

Table 2. Frequency dependence relation and average depth at all lapse times.

The variation of $Q_{c}$ values versus frequency at lapse time $10 \mathrm{~s}$ is displayed in Figure 6 and is tabulated in Table 2. In this lapse time, the average penetration depths of the coda waves are 61, 59, 57, and $63 \mathrm{~km}$ for WA, NWCI, SSZ, and Zagros, respectively. These depths are approximately proportional to the crustal thickness which varies from about $47 \mathrm{~km}$ beneath WA to $69 \mathrm{~km}$ beneath SSZ as reported by [Shad Manaman et al., 2011; Motaghi et al., 2017; Movaghari and Deloei, 2020]. In other words, our results indicate that the attenuation of Zagros is less than SSZ for all frequencies at this lapse time. This may be due to the difference between tectonic setting and seismicity rate of these zones. The Zagros has made of very thick sedimentary rocks with very high seismicity, whereas SSZ has made of metamorphic rocks with very low seismicity. The presence of metamorphic rocks and also volcanoes of late Cretaceous and early Miocene can be the reason of higher attenuation of SSZ. 


\section{Rouhollah Amiri Fard et al.}
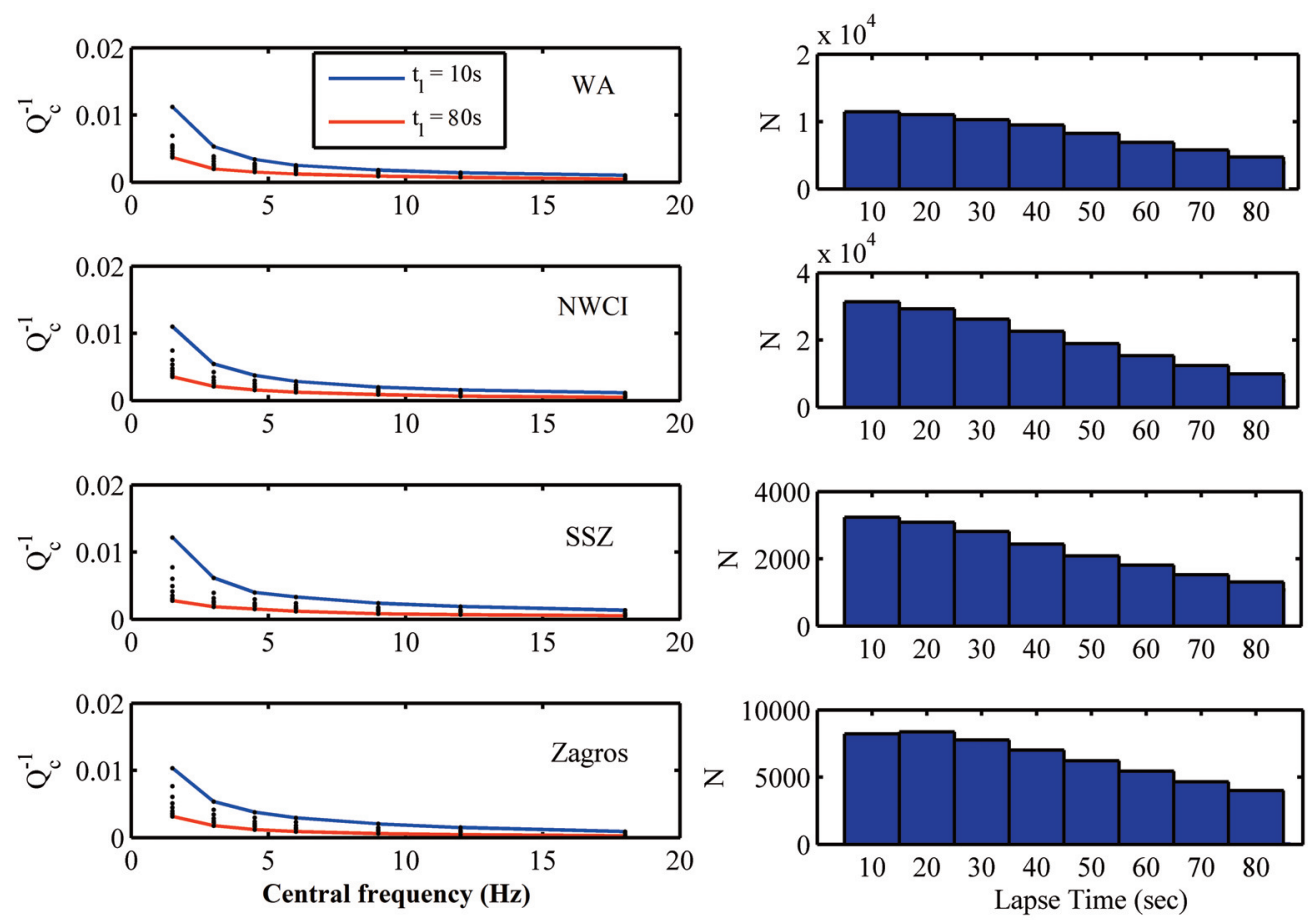

Figure 5. The average $Q_{c}^{-1}$ versus central frequency for regions of WA, NWCI, SSZ, and Zagros zone (left). The blue and red line indicate attenuation at lapse time 10 and 80s. Number of data versus lapse time (right) for each region.

The frequency dependency of $Q_{c}$ values has been determined by means of $Q_{0} f^{n}$ at each lapse time. $Q_{0}$ and $n$ are influenced by different parameters (e.g. degree of fracturing, subsurface material and seismicity of the region) and they have a good correlation with geological observations, seismotectonic, and seismicity [Jin and Aki, 1988]. In our study, the low $Q_{0}$ values $\left(Q_{0}<200\right)$ indicate that all of the zones are tectonically and seismically active. The estimated average frequency dependencies are presented in Table 2 for dataset with epicentral distances less than $100 \mathrm{~km}$. The increase in the $Q_{0}$ and $Q_{c}$ values and decrease in the values of $n$ with increasing lapse time can be observed from table 2. Observations of the exponent $n$, describing the frequency dependency of $Q_{o}$ in several regions of the world indicate that higher values of $n$ are reported for tectonically active areas [Singh and Herrmann 1983].

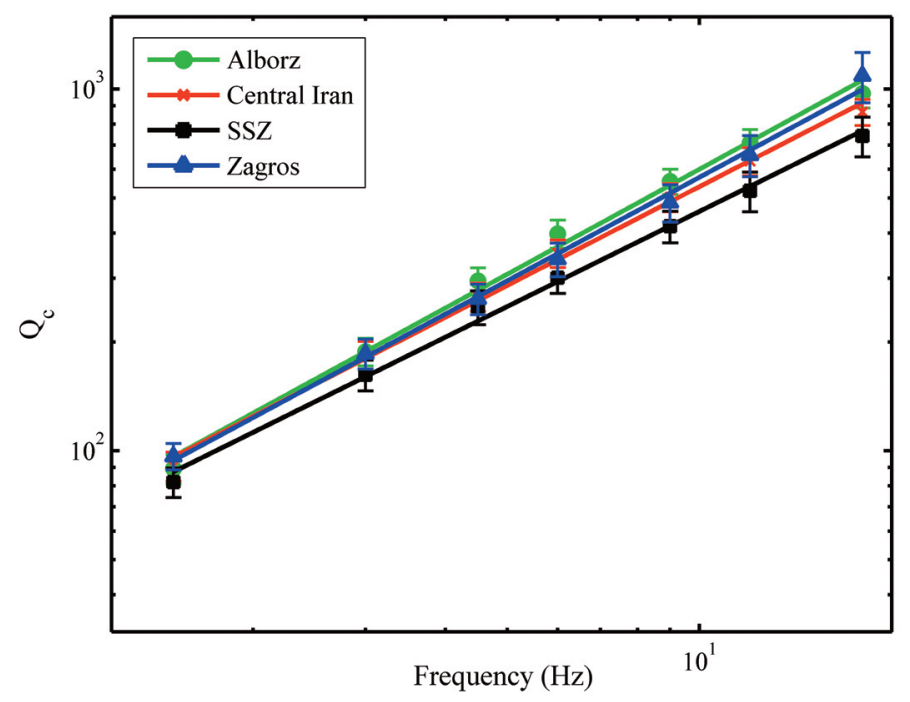

Figure 6. Variation of estimated $Q_{c}$ values versus frequency at lapse time $10 \mathrm{~s}$. 
Similarly, a correlation between $Q_{0}$ and $n$ seems to be existing worldwide: $n$ appears to decrease as $Q_{0}$ increases. This tendency was observed by Xie and Mitchell [1990] for Lg coda- $Q$ in continental Africa, whereas Nuttli [1988] suggested that smaller values of $n$ are associated with larger values of $Q_{0}$, as is generally true throughout the world.

Most studies show an increase in $\underline{Q}_{c}$ with increasing lapse time [Kumar et al. 2005]. This effect can be caused by several factors but likely indicates an increase in $Q_{c}$ with depth, as a greater volume of less complex upper mantle material is included in the sampling volume [Zelt et al. 1999, Mahood et al., 2009]. Any increase of $Q$ values with depth would cause the increasing of coda- $Q$ with lapse time, since at later lapse times, the coda- $Q$ is an estimate of the average $Q$ over a larger volume. The variations of $Q_{0}$ and $n$ versus lapse time for two datasets is depicted in Figure 7 and Figure 8. As it can be seen in Figure 7-a, the $Q_{0}$ values of Zagros and SSZ become larger than those of WA and NWCI at lapse time about $20 \mathrm{~s}$. The average depth at this lapse time is about $75 \mathrm{~km}$, and it approximately coincides with a low velocity zone beneath WA and NWCI and with a high velocity (Arabian lithosphere) zone beneath Zagros and SSZ [Sodoudi et al., 2009; Mohammadi et al., 2013; Motaghi et al., 2017; Rastgoo et al., 2018]. The coda waves at lapse times longer than $20 \mathrm{~s}$, travel through the low velocity and highly dissipating media zone beneath WA and NWCI while they travel through the Arabian lithosphere with high velocity beneath Zagros and SSZ. In the Arabic lithosphere, radioactive decay is low because of rigidity and high age of Arabic lithosphere [Stern and Johnson, 2010]. Therefore lower radioactivity causes lower temperature and this low temperature of the Arabian lithosphere may be a reason for low attenuation of Zagros and SSZ. Shad Manaman et al. [2011] also have reported a high velocity layer beneath Zagros and SSZ and a low shear velocity zone beneath WA and NCWI at depth $100 \mathrm{~km}$ which confirm our results.
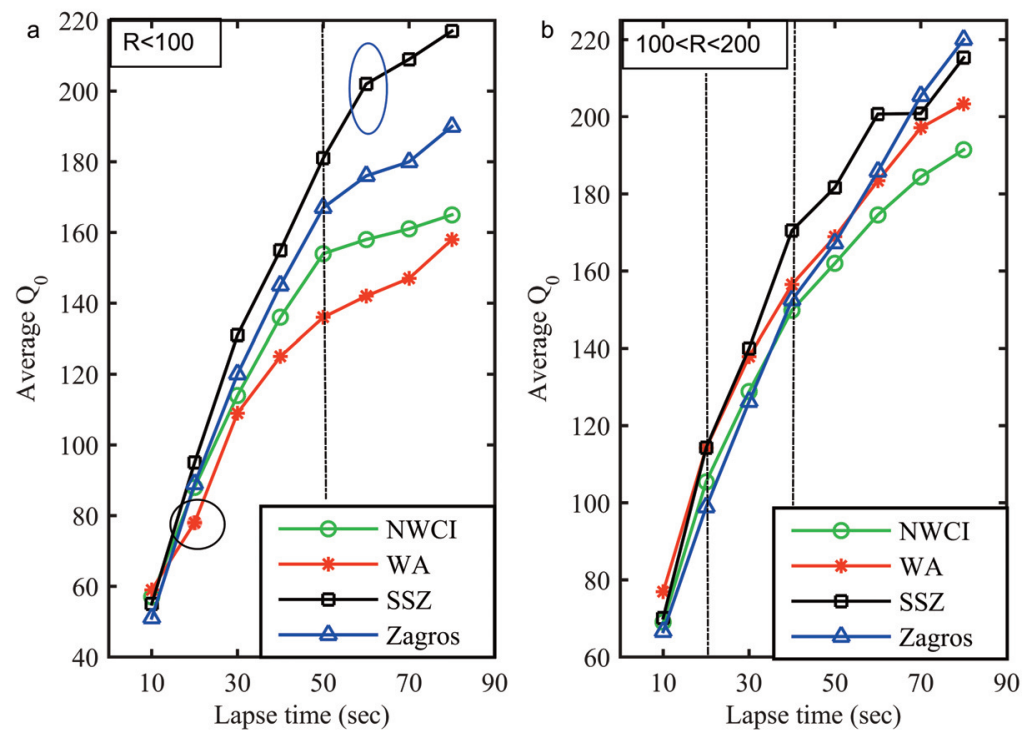

Figure 7. The variation of average $Q_{0}$ versus lapse time. (a) Results for dataset with $R<100$. (b) Results for dataset with $100<\mathrm{R}<200 \mathrm{~km}$. the vertical lines show the breaks at two dataset.

A slight decrease of $Q_{0}$ is seen at lapse time $20 \mathrm{~s}$ for WA that is specified by a circle in Figure 7-a. In the contrary, $n$ parameter has a slight increase (Figure 8-a). This confirms the presence of high dissipating media in depth of 74 $\mathrm{km}$ and the slight decrease of $Q_{0}$ may be related to the existence of Lithosphere-Asthenosphere boundary (LAB) at this depth. Farrokhi et al. [2015] reported the existence of shallow Lithosphere-Asthenosphere Boundary (LAB) at depth of $78 \mathrm{~km}$ and change in the elastic properties due to the partial melting of the oceanic crust of the South Caspian basin which is very well confirm our results. The study of Rastgoo et al. [2018] also shows a low velocity zone at depth range of 50-100 km for WA. Their results support the lithospheric delamination model proposed by Shabanian et al. [2012] for relation of this low velocity zone to the raised hotter mantle.

In both Figure 7-a and Figure 8-a, a break can be seen in Zagros and NCWI curves at lapse time $50 \mathrm{~s}$ which is proportional to the depth of $136 \mathrm{~km}$ and $129 \mathrm{~km}$, respectively. This break has appeared at lapse time $60 \mathrm{~s}$ and depth 


\section{Rouhollah Amiri Fard et al.}

of $145 \mathrm{~km}$ for SSZ. According to the suggested model of Mohammadi et al. [2013], a low velocity zone exists beneath Zagros and SSZ in depth range of 100-150 km. Their results show that its depth increases from Zagros toward SSZ which confirm our results. They related the low velocity zone to the remnant of the fossil Neo-Tethyan subduction within the Arabian lithosphere. The combination of our results with Mohammadi et al. [2013] emphasizes low velocity zone may be due to the partial melting of the remnant of the fossil Neo-Tethyan. In more dataile, we can see a small decrease of $Q_{c}$ at lapse time $70 \mathrm{~s}$ for WA and Zagros. Depth at this lapse time for both WA and Zagros are proportional to LAB.
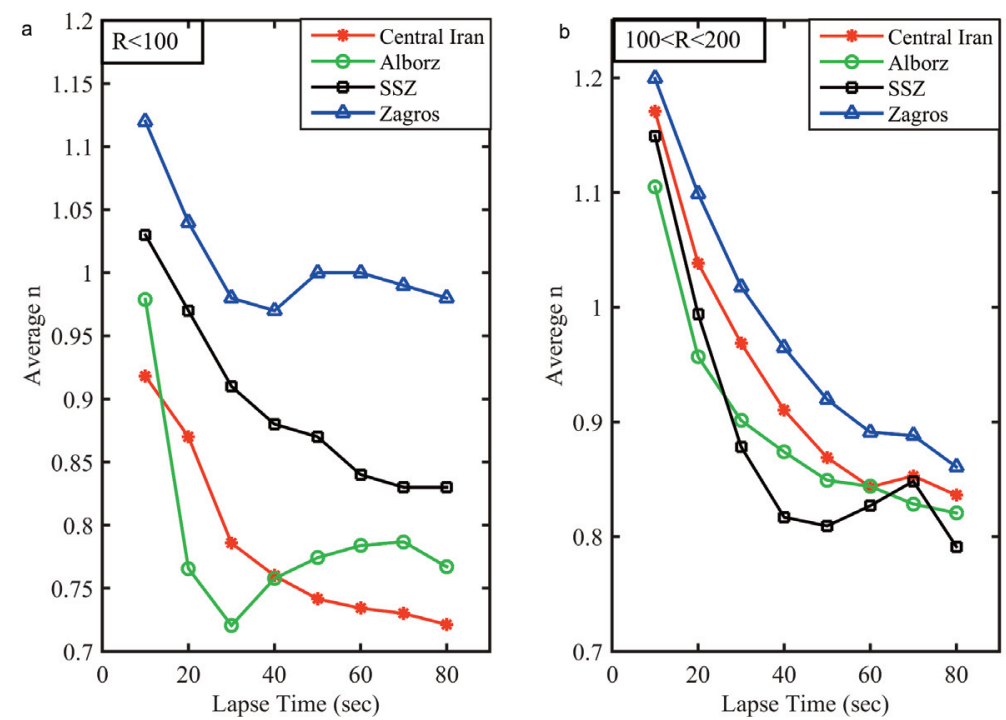

Figure 8. The variation of mean $\mathrm{n}$ versus lapse time for epicentral distances $\mathrm{R}<100 \mathrm{~km}$ and $100<\mathrm{R}<200$.

In order to investigate the variations of $Q_{0}$ in the deeper layers, the dataset with the epicentral distance range of 100 to $200 \mathrm{~km}$ has also been considered (Figure 7-b). In Figure 7-b, two breaks can be seen at lapse time 20 and $40 \mathrm{~s}$. The first break on Figure7-b is proportional to the break at lapse time $50 \mathrm{~s}$ on the Figure 7-a. However, the second break at lapse time $40 \mathrm{~s}$ on Figure 7-b is proportional to the depth of $178 \mathrm{~km}$ for SSZ. This may coincides with the bottom of Arabian lithosphere which is subducted beneath Iran plateau.

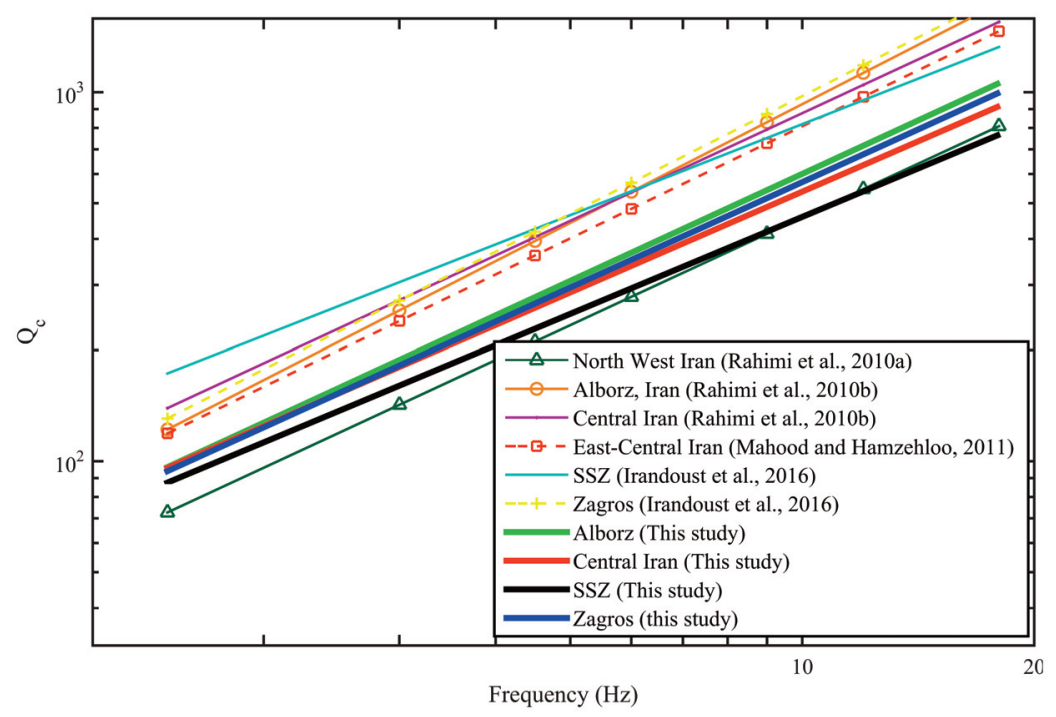

Figure 9. Comparison of $Q_{c}$ values with reported $Q_{c}$ for other parts of Iran at lapse time 30s. 


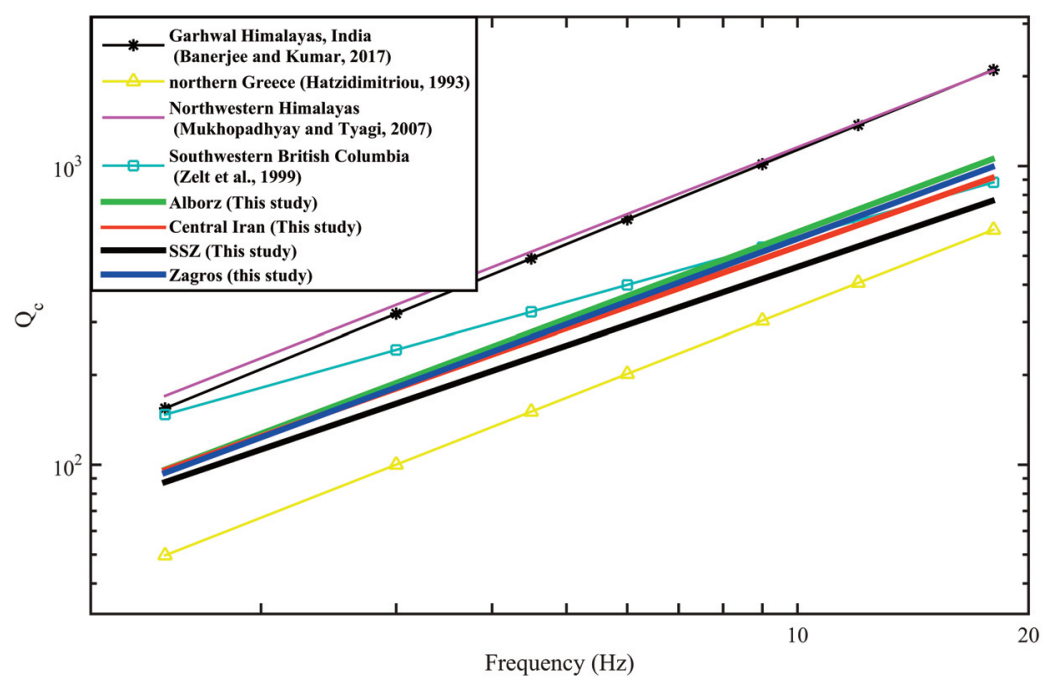

Figure 10. Comparison of $Q_{c}$ values with reported $Q_{c}$ for other parts of world at lapse time 30s.

The comparison of the obtained frequency dependency relation of $Q_{c}$ with previous studies in different part of Iran is shown in Figure 9 for lapse time $30 \mathrm{~s}$. We observed that the rate of changes of $Q_{c}$ in the present study is similar to those of other studies. The Figure 9 demonstrates that obtained $Q c$ values are lower than other results except Rahimi et al. [2010].This difference is almost due to the different geological structures, different data set and different epicentral distances. Similarity between our results and result of Rahimi et al. [2010] can be due to this fact that all of studied area of Rahimi et al. [2010] is a small part of our present area of study.

The results have also compared with other active regions of the world [Hatzidimitriou, 1993; Zelt et al., 1999; Mak et al., 2004; Mukhopadhyay and Tyagi, 2007; Banerjee and Kumar, 2017] as shown in Figure 10. Our results are in good agreement with other seismically active regions of the world. That is, tectonically similar areas have very similar coda $Q$ which reported by Havskov et al. [2016].

\section{Conclusion}

In the present study, coda wave quality factor for 7 central frequencies at 8 lapse times have been estimated using single back-scattering method. The average frequency dependency of $Q_{c}$ for lapse time $10 \mathrm{~s}$ is $Q_{c}=$ $(62 \pm 1) \mathrm{f}^{(0.91 \pm 0.01)}, Q_{c}=(58 \pm 1) \mathrm{f}^{(0.97 \pm 0.01)}, Q_{c}=(55 \pm 2) \mathrm{f}^{(1.03 \pm 0.01)}$, and $Q_{c}=(51 \pm 1) \mathrm{f}^{(1.12 \pm 0.01)}$ for WA, NWCI, SSZ, and Zagros, respectively. The $Q_{c}$ results of the west of Iran is comparable with those of seismically active regions of world. The average $Q_{c}$ values and their frequency-dependency relationships show that the medium is highly heterogeneous.

The trend of $Q_{0}$ shows a decrease at lapse time $20 \mathrm{~s}$ for WA (depth $\sim 74 \mathrm{~km}$ ) which may be due to the high dissipating media that coincided with the LAB beneath Alborz.

In order to investigate the variations of mean $Q_{0}$ in the deeper layers, the dataset with the epicentral distance ranges between 100 and $200 \mathrm{~km}$ have also been analyzed. A change in the trend of $Q_{0}$ at lapse time 40 s can be observed that is proportional to the depth of 163, 165, 178, and $181 \mathrm{~km}$ for WA, NWCI, SSZ, and Zagros, respectively. This break for SSZ and Zagros may coincide with the bottom of Arabian lithosphere. Therefore, due to the rich database, our results are more robust than previous studies in Iran and bring a broad scale view to the heterogeneous and seismic activity in the west of Iran plateau.

Acknowledgements. This research was supported by International Institute of Earthquake Engineering and Seismology under project number 5403-738. Many thanks to anonymous reviewers and the Editor for their helpful comments and constructive reviews that fully improved our manuscript. The authors are grateful to the International Institute of 


\section{Rouhollah Amiri Fard et al.}

Earthquake Engineering and Seismology (IIEES), Iranian Seismological Center (IRSC), and Institute for Advanced Studies in Basic Sciences (IASBS) for providing the required waveforms for this study.

\section{References}

Agard, P., J. Omrani, L. Jolivet and F. Mouthereau (2005). Convergence history across Zagros (Iran): constraints from collisional and earlier deformation, Int. J. Earth Sci., 94, 3, 401-419.

Ahmadzadeh, S., S. Parolai, G. Javan Doloei and A. Oth (2017). Attenuation characteristics, source parameters and site effects from inversion of S waves of the March 31, 2006 Silakhor aftershocks, Annals of Geophysics, v. 60, 6(sup), 668.

Ahmadzadeh, S., G. Javan Doloei, S. Parolai and A. Oth (2019). Non-parametric spectral modelling of source parameters, path attenuation and site effects from broad-band waveforms of the Alborz earthquakes (20052017), Geophys. J. Int., v219, no.3, p.1514-1531.

Aki, K. (1969). Analysis of the seismic coda of local earthquakes as scattered waves, J. Geophys. Res., 74, 2, 615-631.

Aki, K. (1981). Source and scatering effects on the spectra of small local earthquakes, Bull. Seism. Soc. Am., 71, 6, 1687-1700.

Aki, K. and B. Chouet (1975). Origin of coda waves: source, attenuation, and scattering effects, J. Geophys. Res., 80, 23, 3322-3342.

Alavi, M. and S. Kishvar (1991). Tectonic map of the Middle East: geological survey of Iran.

Allen, M., M. Ghassemi, M. Shahrabi and M. Qorashi (2003). Accommodation of late Cenozoic oblique shortening in the Alborz range, northern Iran, J. Struct. Geol., 25, 5, 659-672.

Allen, M., J. Jackson and R. Walker (2004). Late Cenozoic reorganization of the Arabia-Eurasia collision and the comparison of short-term and long-term deformation rates, Tectonics, 23, 2, https://doi.org/10.1029/2003TC001530

Amiri Fard, R., G. Javan Doloei, H. Rahimi and M. Farrokhi (2019). Attenuation of P and S waves in Western part of Iran, Geophys. J. Int., 218, 2, 1143-1156.

Bachmanov, D., V. Trifonov, K. T. Hessami, A. Kozhurin, T. Ivanova, E. Rogozhin, M. Hademi and F. Jamali (2004). Active faults in the Zagros and central Iran, Tectonophysics, 380, 3-4, 221-241.

Banerjee, S. and A. Kumar (2017). Determination of seismic wave attenuation for the Garhwal Himalayas, India, Geosci. Res.., 2, 2, 105-126.

Berberian, F., I. Muir, R. Pankhurst and M. Berberian (1982). Late Cretaceous and early Miocene Andean-type plutonic activity in northern Makran and Central Iran, J. Geol. Soc., 139, 5, 605-614.

Berberian, M. (1983). The southern Caspian: a compressional depression floored by a trapped, modified oceanic crust, Canadian J. Earth Sci., 20, 2, 163-183.

Berberian, M. and G. King (1981). Towards a paleogeography and tectonic evolution of Iran, Canadian J. Earth Sci., 18, 2, 210-265.

Chung, J.-K., Y.-L. Chen and T.-C. Shin (2009). Spatial distribution of coda Q estimated from local earthquakes in Taiwan area, Earth, Planets Space, 61, 9, 1077-1088.

Doloei, J. and R. Roberts (2003). Crust and uppermost mantle structure of Tehran region from analysis of teleseismic P-waveform receiver functions, Tectonophysics, 364, 3-4, 115-133.

Fard, N. G., A. Sorbi and M. Arian (2015). Active Tectonics of Kangavar Area, West Iran, Open J. Geology, 5, $06,422$.

Farrokhi, M., H. Hamzehloo, H. Rahimi and M. Allamehzadeh (2015). Estimation of coda-wave attenuation in the central and eastern Alborz, Iran, Bull. Seism. Soc. Am., 105, 3, 1756-1767.

Gao, L., L. Lee, N. Biswas and K. Aki (1983). Comparison of the effects between single and multiple scattering on coda waves for local earthquakes, Bull. Seism. Soc. Am., 73, 2, 377-389.

Ghorbani, M. (2013). A summary of geology of Iran, in The Economic Geology of Iran, Springer, 45-64.

Hamzehloo, H., A. Alikhanzadeh, M. Rahmani and A. Ansari (2012). Seismic hazard maps of Iran, in Proceedings 15th World Conference on Earthquake Engineering.

Hatzidimitriou, P. (1993). Attenuation of coda waves in Northern Greece, Pure Appl. Geophys., 140, 1, 63-78.

Havskov, J., M. B. Sørensen, D. Vales, M. Özyazıcıŏlu, G. Sánchez and B. Li (2016). Coda Q in different tectonic areas, influence of processing parameters, Bull. Seism. Soc. Am., 106, 3, 956-970. 


\section{Coda wave attenuation in west of Iran plateau}

Hessami, K., F. Jamali and H. Tabassi (2003). Major active faults of Iran, IIEES, Tehran.

Irandoust, M. A., F. Sobouti and H. Rahimi (2016). Lateral and depth variations of coda Q in the Zagros region of Iran, J. Seismol., 20, 1, 197-211.

Jackson, J. and T. Fitch (1981). Basement faulting and the focal depths of the larger earthquakes in the Zagros Mountains (Iran), Geophys. J. Int., 64, 3, 561-586.

Jin, A. and K. Aki (1988). Spatial and temporal correlation between coda Q and seismicity in China, Bull. Seism. Soc. Am., 78, 2, 741-769.

Kaviani, A. (2004). La châin de collision continentale du Zagros (Iran): structure lithosphérique par analyse de données sismologique: Université Joseph-Fourier-Grenoble I.

Kaviani, A., E. Sandvol, X. Bao, G. Rümpker and R. Gök (2015). The structure of the crust in the Turkish-Iranian Plateau and Zagros using Lg Q and velocity, Geophys. J. Int., 200, 2, 1254-1268.

Ma'hood, M., H. Hamzehloo and G. Doloei (2009). Attenuation of high frequency P and S waves in the crust of the East-Central Iran, Geophys. J. Int., 179, 3, 1669-1678.

Maggi, A., J. Jackson, K. Priestley and C. Baker (2000). A re-assessment of focal depth distributions in southern Iran, the Tien Shan and northern India: Do earthquakes really occur in the continental mantle? Geophys. J. Int., 143, 3, 629-661.

Mak, S., L. Chan, A. Chandler and R. Koo (2004). Coda Q estimates in the Hong Kong region, J. Asian Earth Sci.., 24, 1, 127-136.

Mohammadi, E., F. Sodoudi, R. Kind and M. Rezapour (2013). Presence of a layered lithosphere beneath the Zagros collision zone, Tectonophysics, 608, 366-375.

Motaghi, K., E. Shabanian, M. Tatar, M. Cuffaro and C. Doglioni (2017). The south Zagros suture zone in teleseismic images, Tectonophysics, 694, 292-301.

Movaghari, R. and G.J., Doloei (2020). 3-D crustal structure of the Iran plateau using phase velocity ambient noise tomography, Geophys. J. Int., 220, 3, 1556-1568.

Mukhopadhyay, S. and C. Tyagi (2007). Lapse time and frequency-dependent attenuation characteristics of coda waves in the Northwestern Himalayas, J. Seismol., 11, 2, 149-158.

Mukhopadhyay, S., C. Tyagi and S. Rai (2006). The attenuation mechanism of seismic waves in northwestern Himalayas, Geophys. J. Int., 167, 1, 354-360.

Naghavi, M., H. Rahimi, A. Moradi and S. Mukhopadhyay (2017). Spatial variations of seismic attenuation in the North West of Iranian plateau from analysis of coda waves, Tectonophysics, 708, 70-80.

Pulli, J. J. (1984). Attenuation of coda waves in New England, Bull. Seism. Soc. Am., 74, 4, 1149-1166.

Rahimi, H. and H. Hamzehloo (2008). Lapse time and frequency-dependent attenuation of coda waves in the Zagros continental collision zone in Southwestern Iran, J. Geophys. Eng., 5, 2, 173.

Rahimi, H., H. Hamzehloo and N. Kamalian (2010). Estimation of coda and shear wave attenuation in the volcanic area in SE Sabalan Mountain, NW Iran, Acta Geophys., 58, 2, 244-268.

Rastgoo, M., H. Rahimi, K. Motaghi, E. Shabanian, F. Romanelli and G. F. Panza (2018). Deep structure of the Alborz Mountains by joint inversion of P receiver functions and dispersion curves, Phys. Earth and Planet. Int., 277, 70-80.

Sato, H. (1977). Energy propagation including scattering effects single isotropic scattering approximation, J. Phys. Ear., 25, 1, 27-41.

Sato, H. (1988). Fractal interpretation of the linear relation between logarithms of maximum amplitude and hypocentral distance, J. Geophys. Res., 15, 4, 373-375.

Sato, H., M. C. Fehler and T. Maeda. (2012). Seismic wave propagation and scattering in the heterogeneous earth, Second Ed., Springer, New York, 1-496.

Şengör, A., D. Altıner, A. Cin, T. Ustaömer and K. Hsü (1988). Origin and assembly of the Tethyside orogenic collage at the expense of Gondwana Land, Geolo. Soc. London, Special Publication, 37, 1, 119-181.

Shabanian, E., V. Acocella, A. Gioncada, H. Ghasemi and O. Bellier (2012). Structural control on volcanism in intraplate post collisional settings: Late Cenozoic to Quaternary examples of Iran and Eastern Turkey, Tectonics. 31, 3, doi:10.1029/2011TC003042

Shad Manaman, N., H. Shomali and H. Koyi (2011). New constraints on upper-mantle S-velocity structure and crustal thickness of the Iranian plateau using partitioned waveform inversion, Geophys. J. Int., 184, 1, 247-267.

Shapiro, N., M. Campillo, L. Margerin, S. Singh, V. Kostoglodov and J. Pacheco (2000). The energy partitioning and the diffusive character of the seismic coda, Bull. Seism. Soc. Am., 90, 3, 655-665. 


\section{Rouhollah Amiri Fard et al.}

Singh, S. and R. B. Herrmann (1983). Regionalization of crustal coda Q in the continental United States, J. Geophys. Res.: Solid Earth, 88, B1, 527-538.

Snyder, D. B. and M. Barazangi (1986). Deep crustal structure and flexure of the Arabian plate beneath the Zagros collisional mountain belt as inferred from gravity observations, Tectonics, 5, 3, 361-373.

Sodoudi, F., X. Yuan, R. Kind, B. Heit and A. Sadidkhouy (2009). Evidence for a missing crustal root and a thin lithosphere beneath the Central Alborz by receiver function studies, Geophys. J. Int., 177, 2, 733-742.

Stampfli, G. M. and G. Borel (2002). A plate tectonic model for the Paleozoic and Mesozoic constrained by dynamic plate boundaries and restored synthetic oceanic isochrons, Earth Planet. Sci. Lett., 196, 1, 17-33.

Stern, R. J. and P. Johnson (2010). Continental lithosphere of the Arabian Plate: a geologic, petrologic, and geophysical synthesis, Earth-Sci. Rev., 101, 1-2, 29-67.

Stocklin, J. (1968). Structural history and tectonics of Iran: a review, AAPG Bulletin, 52, 7, 1229-1258.

Stoneley, R. (1981). The geology of the Kuh-e Dalneshin area of southern Iran, and its bearing on the evolution of southern Tethys, J. Geolo. Soc., 138, 5, 509-526.

Talebian, M. and J. Jackson (2004). A reappraisal of earthquake focal mechanisms and active shortening in the Zagros mountains of Iran, Geophys. J. Int., 156, 3, 506-526.

Tatar, M. (2001). Etude sismotectonique de deux zones de collision continentale: le Zagros central et l'Alborz (Iran): Grenoble 1.

Vernant, P., F. Nilforoushan, J. Chery, R. Bayer, Y. Djamour, F. Masson, H. Nankali, J.-F. Ritz, M. Sedighi and F. Tavakoli (2004). Deciphering oblique shortening of central Alborz in Iran using geodetic data, Earth Planet. Sci. Lett., 223, 1-2, 177-185.

Wennerberg, L. (1993). Multiple-scattering interpretations of coda-Q measurements, Bull. Seism. Soc. Am., 83, 1, 279-290.

Zelt, B., N. Dotzev, R. Ellis and G. Rogers (1999). Coda Q in southwestern British Columbia, Canada, Bull. Seism. Soc. Am., 89, 4, 1083-1093. 